\title{
Medicolegal lessons learned from thyroidectomy-related lawsuits: an analysis of judicial precedents in South Korea from 1998 to 2019
}

\author{
Sungkyoung Choi ${ }^{1 \#}$, Suhwan Shin ${ }^{2,3 \#}$, Won Lee ${ }^{4}$, Soon-Min Choi ${ }^{5}$, Sang-Wook Kang ${ }^{5}$ \\ ${ }^{1}$ Division of Medical Law and Ethics, Department of Medical Humanities and Social Sciences, Yonsei University College of Medicine, Seoul, Korea; \\ ${ }^{2}$ Blue Urology Clinic, Seoul, Korea; ${ }^{3}$ Department of Medical Law and Ethics, Graduate School, Yonsei University, Seoul, Korea; ${ }^{4}$ Department of \\ Nursing, Chung-Ang University, Seoul, Korea; ${ }^{5}$ Department of Surgery, Yonsei University College of Medicine, Seoul, Korea \\ Contributions: (I) Conception and design: S Shin, S Choi, SW Kang, W Lee; (II) Administrative support: S Choi; (III) Provision of study materials or \\ patients: S Shin; (IV) Collection and assembly of data: S Shin, S Choi; (V) Data analysis and interpretation: S Shin, S Choi; (VI) Manuscript writing: \\ All authors; (VII) Final approval of manuscript: All authors. \\ \#These authors contributed equally to this work. \\ Correspondence to: Sang-Wook Kang, MD. Department of Surgery, Yonsei University College of Medicine, 50-1, Yonsei-ro, Seodaemun-gu, Seoul \\ 03722, Korea. Email: oralvanco@yuhs.ac.
}

Background: Thyroid cancer is one of the most common cancers in South Korea, and thyroidectomy is still frequently performed. As new diagnostic methods have led to a significant increase in the early detection of thyroid cancer worldwide, medical disputes related to thyroid surgery are also likely to increase. The purpose of this study was to investigate the causes of medical disputes related to thyroidectomy and to identify ways to prevent unnecessary disputes and malpractice.

Methods: We analyzed 35 judicial decisions involving thyroidectomy in South Korea from January 1998 to July 2019.

Results: The most common cause of lawsuits was "performance error during surgery" ( $\mathrm{n}=19)$, especially "recurrent laryngeal nerve (RLN) injury" $(n=7)$, of which five cases were ruled medical malpractice. For lawsuits involving misdiagnosis $(\mathrm{n}=14)$, five regarding fine needle aspiration cytology (FNAC) and frozen section examination were ruled malpractice. The most common malpractice related to informed consent was "lack of explanation about surgery complications" ( $\mathrm{n}=10)$.

Conclusions: Surgeons should follow guidelines to protect themselves from diagnostic error dispute; performing FNAC more often might also prevent lawsuits. When the courts judge the surgeon's negligence in cases of RLN injuries, whether bilateral or unilateral, it is necessary to consider fully the surgeon's efforts to prevent RLN injuries. Providing information and building trust through sufficient patient-doctor communication is crucial.

Keywords: Dissent and disputes; jurisprudence; malpractice; recurrent laryngeal nerve injuries; thyroidectomy

Submitted Mar 24, 2020. Accepted for publication Sep 04, 2020.

doi: $10.21037 / g s-20-398$

View this article at: http://dx.doi.org/10.21037/gs-20-398

\section{Introduction}

Thyroidectomy is a common surgical procedure, mainly used to treat thyroid tumors or hyperthyroidism. However, because it sometimes results in complications such as laryngeal nerve palsy or hypoparathyroidism that lower patients' quality of life, it can be a major trigger for medical lawsuits (1-4). As improvements in diagnostic methods have led to a significant increase in the early detection of thyroid cancer worldwide (5-7), medical disputes related to thyroid surgery are also likely to increase. Medical lawsuits 
have economically and psychologically adverse effects on both physicians and patients, irrespective of the presence of medical malpractices (2). Accordingly, to protect surgeons from medical lawsuits and to ensure that patients have safer surgeries, efforts to prevent disputes in advance are necessary.

South Korea has one of the highest incidence rates of thyroid cancer worldwide (7). According to the Korea Central Cancer Registry, the incidence of thyroid cancer has increased more than tenfold, from 7.2 per 100,000 people in 1999 to 74.7 per 100,000 people in 2012 (8). The incidence rate has declined slightly since 2013, but thyroid cancer is still one of the most common cancers in South Korea, and thyroidectomy is still frequently performed (9).

With the country's economic growth and improving awareness of people's rights, the patient-physician relationship in South Korea has shifted from that of "paternalism", where doctors are viewed as absolute authorities, to that of "reciprocity", here patient autonomy is respected, as in other developed countries (10). To further strengthen patients' rights, a mandate requiring physicians to explain to patients the various aspects of their treatment was added to the Medical Service Act in 2016. Accordingly, medical disputes are steadily increasing, and these are resolved through judicial methods such as civil lawsuits or non-judicial methods such as mediations (11).

Among them, medical lawsuit judgments, which include information such as medical accident, patient's allegations, and court decisions, are good tools for identifying the characteristics of medical disputes. Analyzing lawsuit judgments involving thyroidectomy in South Korea might produce meaningful results, but no such study has been conducted so far. The purpose of this study was to investigate the causes of medical disputes and the corresponding court decisions related to thyroidectomy, using lawsuit judgments in order to explore ways to prevent malpractice and unnecessary medical disputes. We present the following article in accordance with the MDAR and STROBE reporting checklist (available at http://dx.doi. org/10.21037/gs-20-398).

\section{Methods}

This study was a retrospective analysis that investigated all lawsuit cases involving thyroidectomy in South Korea from January 1998 to July 2019. We collected written judgments relating to thyroidectomy through the South Korean Supreme Court's written judgment database system. All judgments of the Supreme Court and the lower courts are databased in this system, and anyone can request copies of judgments they are seeking. These copies are provided to the requester after all personally identifiable information is deleted. Therefore, since it is impossible for researchers to collect personally identifiable information and identify individuals via this collection method, approval from a relevant institutional review board (IRB) was not necessary for this study. The study was conducted in accordance with the Declaration of Helsinki (as revised in 2013).

The terms "thyroidectomy" and "thyroid cancer" were used to identify and collect the desired written judgments. The contents of the judgments were then reviewed, and cases in which clinical information was insufficient for analysis and cases in which thyroidectomy was not actually performed but merely mentioned were excluded from our analysis.

The judgments contain information such as the background of the disputes, information on the patients and defendants, the plaintiff's allegations, and the court's decisions. We collected information on the age and sex of the patient, pre/postoperative diagnoses, and the type of surgery from each case. Judicial information such as the type of defendant, lawsuit process, trial outcome, and payment amount were also collected. The plaintiff's allegations concerning the defendant's malpractice were analyzed in two aspects: "treatment-related issues" and "explanationrelated issues". "Treatment-related issues" were classified into four groups: misdiagnosis in the preoperative phase, misdiagnosis in the intraoperative phase, performance error in the intraoperative phase, and improper management in the postoperative phase. All analyses and classifications were performed independently by two researchers (S Choi and S Shin). In case of disagreements between the two, they went through a debate process for reaching consensus. If an agreement still could not be reached, a third researcher (S Kang) conducted additional analysis to confirm the final classification.

\section{Statistical analysis}

Descriptive statistical analyses were conducted using Microsoft Excel 2013 (Microsoft Corporation, Redmond, WA, USA) and IBM SPSS Statistics version 25 for windows (IBM Corporation, Armonk, NY, USA). Categorical variables were presented as frequencies and percentages. For continuous variables, we first performed the ShapiroWilk test to check the data distribution (The distribution 


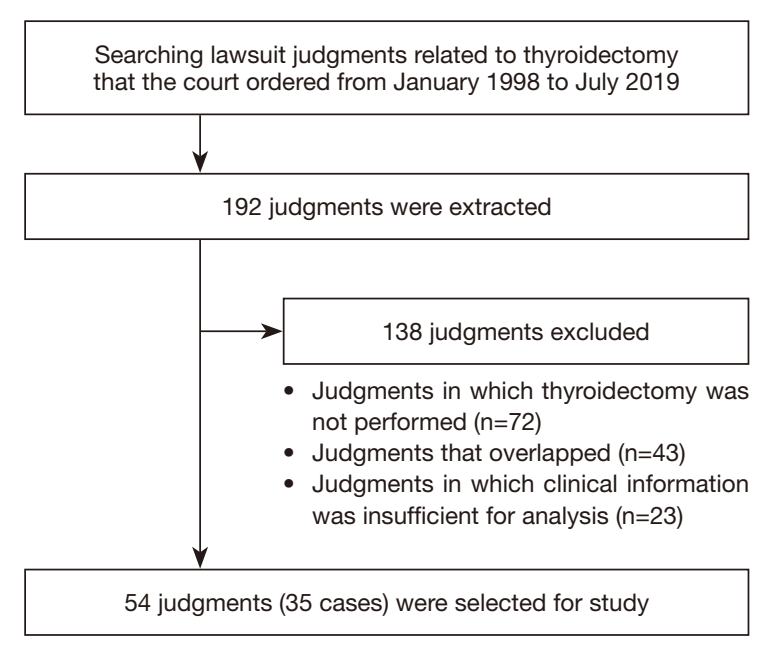

Figure 1 Flowchart on the selection of lawsuit cases.

was considered normal if $\mathrm{P}>0.05$ ). If the continuous variables did not follow the normal distribution, these were presented as the median values and quartile ranges (IQR).

\section{Results}

We retrieved 192 lawsuit cases involving thyroidectomies from the database of the Korean Supreme Court written judgment system and excluded cases according to our selection criteria (Figure 1). After exclusion, 35 cases with 54 lawsuit judgments were selected for this study. Of these, $68.6 \%$ of patients were female and $68.6 \%$ were diagnosed with malignant disease before surgery (Table 1). Regarding surgery, $63.7 \%$ underwent total thyroidectomy and $87.9 \%$ underwent conventional open thyroidectomy. The judicial characteristics of the 35 cases are shown in Table 2. The most common type of defendant was "Medical institution only" (51.4\%). In total, 19 cases (54.3\%) were concluded at the first instance, and $20(57.1 \%)$ were ruled in favor of the plaintiff. The average payment was $\$ 18,182$ (USD) per case (with a range of $\$ 1,364$ to $\$ 118,182$ ).

Table 3 shows the plaintiff's allegation concerning treatment-related issues at each phase of surgery and the court's decision. Of the 35 lawsuit cases, 33 were included and analyzed. In the preoperative phase, 10 cases claimed misdiagnosis due to "not examin(ing) fine needle aspiration cytology (FNAC)", "misinterpretation of FNAC results", or "failure to detect cancer despite examinations". Of these, only 3 cases in which FNAC was not examined were ruled by the court as being due to physician malpractice; the tumor sizes were 3 to $4,0.4$, and $3.8 \mathrm{~cm}$. Misdiagnosis at the intraoperative phase was associated with frozen section examination (FSE). Two cases showing "disregard for FSE results" were ruled by the court as being due to physician malpractice.

Of the 14 cases of alleged misdiagnosis (10 in the preoperative phase and 4 in the intraoperative phase), 12 involved a conflict between preoperative and postoperative diagnoses, which became the main cause of the dispute (Table 4). Eight patients were diagnosed with malignant tumors or atypical cells before surgery, but their final postoperative diagnoses were benign tumors or thyroiditis that did not need thyroidectomy. Therefore, these eight claimed that "unnecessary surgery" had been caused either by the absence or the misinterpretation of FNAC or FSE results. Three patients claimed that there had been a "diagnosis delay" owing to the failure to detect cancer or lymph node metastasis despite preoperative examinations

There were 19 cases claiming "performance error" during the intraoperative phase; 5 cases of recurrent laryngeal nerve (RLN) injuries, 3 cases of arterial ruptures, and 1 case of sympathetic nerve injury were ruled by the court as being due to physician malpractice. Details of the 9 malpractice cases are shown in Table 5. Regarding RLN injury, while all cases of bilateral injuries were ruled as being due to physician malpractice, only $50 \%$ of unilateral injury cases were ruled as such. The range of the awarded payment was $\$ 16,909$ to $\$ 102,999$. All alleged events regarding arterial ruptures were recognized as being caused by malpractice. The clinical outcomes caused by arterial rupture were death $(n=2)$ or transient ischemic attack $(n=1)$. All awarded payments were above the average amount $(\$ 18,182)$. A patient who experienced sympathetic nerve injury due to excessive traction during surgery had Horner's syndrome. The awarded payment was $\$ 12,475$.

There were 10 cases claiming "improper management" in the postoperative phase. "Negligence in monitoring and emergency responses $(\mathrm{n}=2)$ " and "disregard for the patient's symptoms of nerve injury $(\mathrm{n}=1)$ " were ruled by court as being due to physician malpractice.

Finally, we analyzed the alleged violation of liability for explanation. Figure 2 shows the cases ruled by the court as owing to the physician's violation of liability for explanation. The most common case was the explanation of surgical complications $(\mathrm{n}=10)$. Among those 10 cases, the most common content was "vocal cord paralysis $(n=5)$ ". There were 4 cases in which information about the patient's condition was not provided and 4 cases in which insufficient information was provided about the potential 
Table 1 Patient demographics and clinical information $(\mathrm{n}=35)$

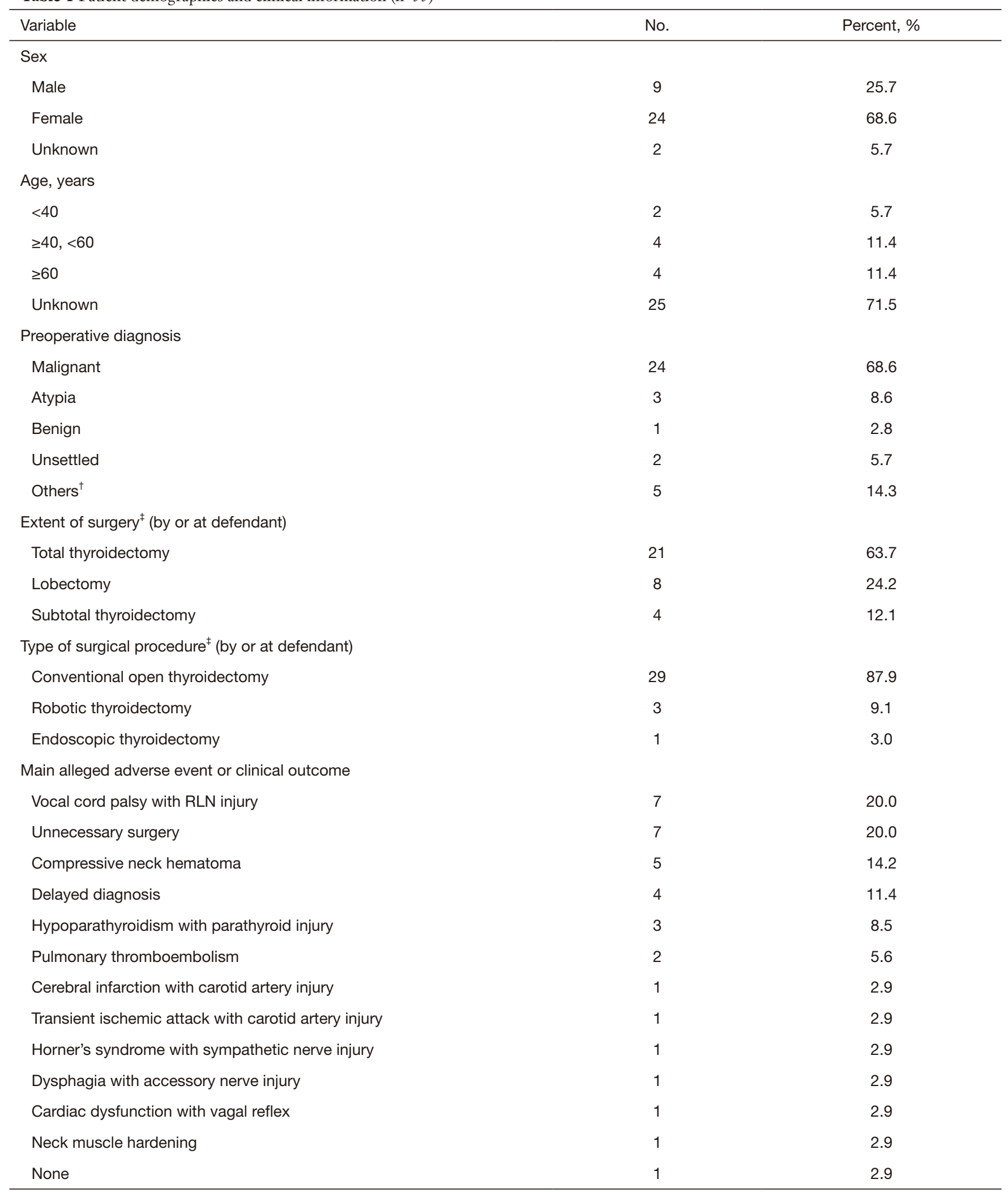

† , 4 hyperthyroidism, 1 Hashimoto's thyroiditis; ${ }^{\ddagger}$, excludes 2 cases operated on at another hospital, not defendant. 
Table 2 Judicial characteristics of the selected 35 cases

\begin{tabular}{|c|c|c|}
\hline Variable & No. & Percent, \% \\
\hline Physician only & 2 & 5.7 \\
\hline Physician and medical institution & 14 & 40.0 \\
\hline Medical institution only & 18 & 51.4 \\
\hline \multicolumn{3}{|l|}{ Process of lawsuit } \\
\hline First instance & 19 & 54.3 \\
\hline Appeal & 13 & 37.1 \\
\hline Final appeal & 3 & 8.6 \\
\hline Settlement decision/conciliation & 7 & 20.0 \\
\hline Dismissal & 8 & 22.9 \\
\hline \multicolumn{3}{|l|}{ Claimed amount (USD $\left.{ }^{\dagger}\right)$} \\
\hline$>150,000$ & 9 & 25.7 \\
\hline $50,000-150,000$ & 12 & 34.3 \\
\hline$<50,000$ & 14 & 40.0 \\
\hline \multicolumn{3}{|l|}{ Payment (USD*) } \\
\hline$>100,000$ & 2 & 5.7 \\
\hline Range (min to max) & \multicolumn{2}{|c|}{$\$ 1,364-\$ 118,182$} \\
\hline
\end{tabular}

${ }^{\dagger}$, USD: United States Dollar, the exchange rate was 1 USD $=1.100 \mathrm{KRW} ;{ }^{\ddagger}$, IQR: interquartile range (Q1-Q3).

benefits and risks of the procedures. There were 3 cases in which information about the possibility of misdiagnosis and limitations of preoperative examinations was not provided.

\section{Discussion}

This study analyzed lawsuits involving thyroidectomy and explored ways to prevent medical malpractice and unnecessary lawsuits. In this study, we found three main results. First, as in previous studies, RLN injury was one of the most common causes of lawsuits in Korea. Second, if surgeons followed guidelines, the court did not recognize misdiagnosis as medical malpractice. Third, informed consent was insufficient, although it is a basic medical duty to explain complications before surgery.

This study showed that the most common cause of lawsuits was "performance error during surgery", and of these, RLN injury was the leading cause. This is consistent with previous studies in Germany and the United States (Table S1) (12-14). The court's judgment on RLN injury differed depending on the extent of damage. All cases of bilateral injury were judged as malpractice; whereas in cases 
Table 3 Alleged liability for treatment-related issues at each phase of surgery

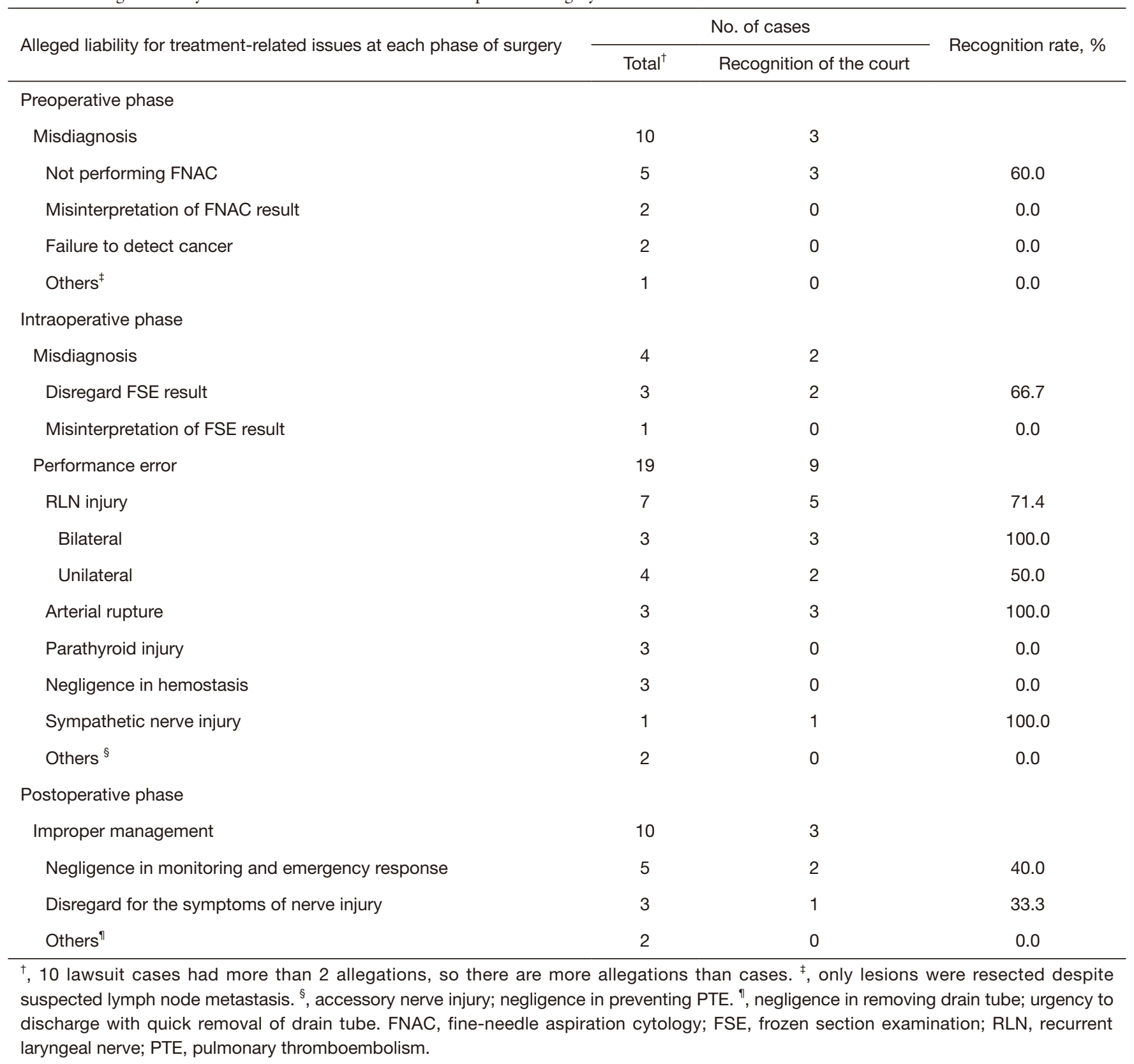

of unilateral injury, only $50 \%$ was judged as malpractice. This trend was the same in Germany (12), and studies in the United States and Italy also showed that the awarded amount for bilateral injuries was greater than that for unilateral injuries $(2,14,15)$. These court decisions indicate that judges tend to regard unilateral injury as an unavoidable complication but bilateral injury as evidence of medical negligence. However, RLN injury, whether bilateral or unilateral, can be caused by other factors in spite of the surgeon's best efforts (15). Therefore, when the courts judge the surgeon's negligence in cases of RLN injuries, whether bilateral or unilateral, it is necessary to consider fully the surgeon's efforts to prevent RLN injuries rather than only regarding the resultant nerve injury. The most basic technique surgeons can take to prevent RLN injury involves first identifying and observing the RLN during 
Table 4 Twelve cases in which diagnosis changed after surgery

\begin{tabular}{|c|c|c|c|c|c|c|c|}
\hline \multirow{2}{*}{$\begin{array}{l}\text { Alleged } \\
\text { adverse event }\end{array}$} & \multirow{2}{*}{ Alleged violation } & \multirow{2}{*}{$\begin{array}{l}\text { Preoperative } \\
\text { examination }\end{array}$} & \multicolumn{3}{|c|}{ Diagnosis } & \multirow{2}{*}{$\begin{array}{c}\text { Extent of surgery } \\
\text { (year) }\end{array}$} & \multirow{2}{*}{$\begin{array}{c}\text { Court } \\
\text { decision }^{\dagger}\end{array}$} \\
\hline & & & Preoperative (size) & FSE result & Final & & \\
\hline $\begin{array}{l}\text { Unnecessary } \\
\text { surgery }\end{array}$ & $\begin{array}{l}\text { Not examining } \\
\text { FNAC }\end{array}$ & $\mathrm{FNAC}^{\ddagger}, \mathrm{CT}$ & PTC $(0.4 \mathrm{~cm})$ & - & $\begin{array}{c}\text { Nodular } \\
\text { hyperplasia }\end{array}$ & TL (in 2014) & $\mathrm{O}$ \\
\hline $\begin{array}{l}\text { Unnecessary } \\
\text { surgery }\end{array}$ & $\begin{array}{l}\text { Not examining } \\
\text { FNAC }\end{array}$ & CT & $\begin{array}{l}\text { Multiple nodule } \\
\qquad(3.8 \mathrm{~cm})\end{array}$ & - & Benign nodule & TL (in 2015) & $\mathrm{O}$ \\
\hline $\begin{array}{l}\text { Unnecessary } \\
\text { surgery }\end{array}$ & $\begin{array}{l}\text { Misinterpretation } \\
\text { of FNAC result }\end{array}$ & US, FNAC & PTC $(0.55 \mathrm{~cm})$ & $\begin{array}{l}\text { Follicular } \\
\text { adenoma }\end{array}$ & HTA & TL (in 2012) & $x$ \\
\hline $\begin{array}{l}\text { Unnecessary } \\
\text { surgery }\end{array}$ & $\begin{array}{l}\text { Disregard for FSE } \\
\text { result }\end{array}$ & $\begin{array}{l}\text { TFT, FNAC, CT } \rightarrow \\
\text { after } 5 \text { months, US }\end{array}$ & PTC & Thyroiditis & $\begin{array}{l}\text { Hashimoto's } \\
\text { Thyroiditis }\end{array}$ & TT (in 2009) & $\mathrm{O}$ \\
\hline $\begin{array}{l}\text { Unnecessary } \\
\text { surgery }\end{array}$ & $\begin{array}{l}\text { Disregard for FSE } \\
\text { result }\end{array}$ & $\begin{array}{l}\text { US, FNAC } \rightarrow \text { after } \\
3 \text { months, FNAC }\end{array}$ & $\begin{array}{l}\text { Indeterminate } \\
\text { atypical nodule } \\
\qquad(1 \mathrm{~cm})\end{array}$ & $\begin{array}{c}\text { Follicular } \\
\text { hyperplasia }\end{array}$ & $\begin{array}{l}\text { Follicular } \\
\text { adenoma }\end{array}$ & TT (in 2012) & $x$ \\
\hline $\begin{array}{l}\text { Unnecessary } \\
\text { surgery }\end{array}$ & $\begin{array}{l}\text { Misinterpretation } \\
\text { of FSE result }\end{array}$ & $\begin{array}{c}\text { FNAC } \rightarrow \text { after } 1 \\
\text { month, FNAC \& CT }\end{array}$ & $\begin{array}{l}\text { Malignant tumor } \\
\quad(1.57 \mathrm{~cm})\end{array}$ & $\begin{array}{c}\text { Follicular } \\
\text { variant of PTC }\end{array}$ & $\begin{array}{l}\text { Follicular } \\
\text { adenoma }\end{array}$ & TT (in 2005) & $x$ \\
\hline $\begin{array}{l}\text { Unnecessary } \\
\text { surgery }\end{array}$ & $\begin{array}{l}\text { Not examining } \\
\text { FNAC for LN }\end{array}$ & FNAC, CT & $\begin{array}{l}\text { PTC with LN } \\
\text { enlargement }\end{array}$ & - & $\begin{array}{l}\text { Tumor without } \\
\text { LNM }\end{array}$ & $\begin{array}{c}\text { TT with LN } \\
\text { dissection (in 2009) }\end{array}$ & $x$ \\
\hline $\begin{array}{l}\text { Delayed } \\
\text { diagnosis }\end{array}$ & $\begin{array}{l}\text { Not examining } \\
\text { FNAC }\end{array}$ & US & Cancer $(3-4 \mathrm{~cm})$ & - & $\begin{array}{c}\text { Cancer with } \\
\text { LNM }\end{array}$ & $\begin{array}{c}\text { TT without LN } \\
\text { dissection (in 2004) }\end{array}$ & $\mathrm{O}$ \\
\hline
\end{tabular}

${ }^{\dagger}$, O: recognition of defendant's malpractice; X: dismissal for claim. ${ }^{\ddagger}$, examination performed at another hospital before visiting the defendant (about 10 days prior). ${ }^{\S}$, diagnosis in another hospital after visiting the defendant. US, ultrasonography; FNAC, fine-needle aspiration cytology; FSE, frozen section examination; TFT, thyroid function test; PTC, papillary thyroid carcinoma; TT, total thyroidectomy; TL, thyroid lobectomy; HTA, hyalinizing trabecular adenoma; LNM, lymph node metastasis.

surgery $(16,17)$, and, second, recording the details of RLN preservation identified is necessary $(12,14,18)$. For RLN identification, the use of intraoperative neurophysiologic monitoring (IONM) can be considered. Many reports demonstrate that IONM can help prevent RLN injury, especially bilateral injury (19-24). In Germany, according to Dralle, some disputes were caused by not using IONM in thyroidectomy or by not using IONM in accordance with international standards (12). However, so far no cases of dispute about the use of IONM have been reported in countries other than Germany (Table S1) $(12-14,25,26)$. In South Korea, the introduction of IONM was relatively late, but the use of IONM will become gradually more common, because National Health Insurance benefits began covering laryngeal nerve monitoring in 2015 (27). Thus, it is advisable that surgeons more actively consider using IONM to prevent RLN injury during surgery, and they must document all actions taken to protect RLN during surgery 
Table 5 Nine performance error cases ruled by the court as due to physician's negligence

\begin{tabular}{llll}
\hline Performance error & Clinical outcome & Age, years & Trial outcome \\
\hline Unilateral RLN injury & VCP & 42 & Ruled in favor of plaintiff \\
Unilateral RLN injury & VCP & 38 & Ruled in favor of plaintiff \\
Bilateral RLN injury & VCP & 48,000 & Ruled in favor of plaintiff \\
Bilateral RLN injury & VCP & 40,492 \\
Bilateral RLN injury & VCP & 42 & Settlement decision \\
STA rupture & Death due to compressive neck hematoma & $\mathrm{N} / \mathrm{I}$ & Settlement decision \\
ICA rupture & Death after cerebral infraction & $\mathrm{N} / \mathrm{I}$ & Ruled in favor of plaintiff \\
CCA rupture & Transient ischemic attack & $\mathrm{N} / \mathrm{I}$ & Ruled in favor of plaintiff \\
Sympathetic nerve injury & Horner's syndrome & $\mathrm{N} / \mathrm{I}$ & Ruled in favor of plaintiff
\end{tabular}

${ }^{\dagger}$, USD: United States Dollar, the exchange rate was 1 USD =1.100 KRW. STA, superior thyroid artery; CCA, common carotid artery; ICA, internal carotid artery; VCP, vocal cord paralysis; N/l, no information.

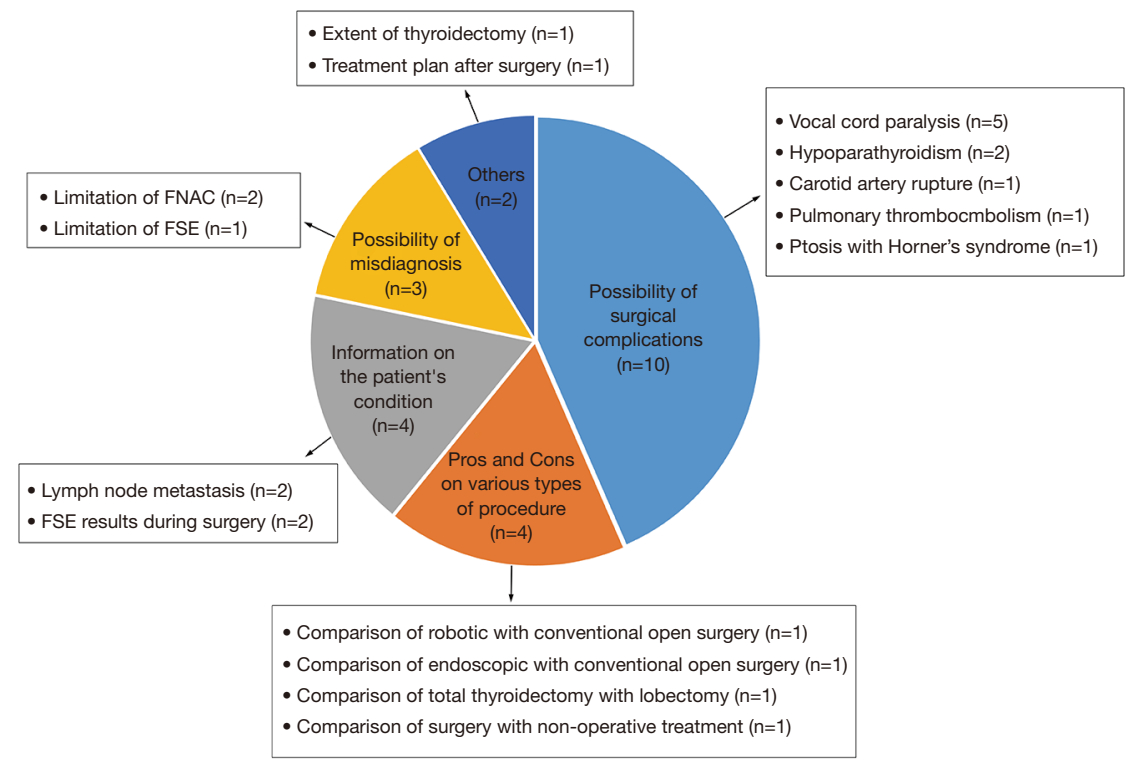

Figure 2 Cases of violation of liability for explanation. ${ }^{\dagger}$, two lawsuit cases had more than two contents so that there are more contents than cases.

to protect themselves from disputes.

In the cases of a misdiagnosis, the court judged that if the physicians diagnosed according to the guidelines, misdiagnosis was not the fault of the physicians, even if the diagnosis changed after the surgery. However, cases in which "FNAC was not performed before surgery" or in which "total thyroidectomy went ahead as planned even though the FSE result turned out non-cancer" were ruled as malpractice. These results have two implications.
First, thyroidectomy is vulnerable above all to disputes involving diagnostic errors, because thyroid cancer, the main reason for thyroidectomy, is difficult to diagnose clearly before surgery due to the limitations of diagnostic testing techniques. Therefore, when deciding whether to undergo surgery, patients should be fully informed about the possibility that the tumor diagnosed as cancerous may turn out, after surgery, to be benign due to the limitations of preoperative examinations $(28,29)$. Second, it would 
be safer to adhere to standardized diagnostic criteria to mitigate legal responsibility for misdiagnosis. In 1996, the American Thyroid Association published its "Treatment guidelines for patients with thyroid nodules and thyroid cancer" (30), and in 2007, South Korean Thyroid Association published similar guidelines more reflective of its sociomedical situation (31). Since its release, both guidelines have been regularly revised. Regarding FNAC, there seems to be a need for more extensive use than the recommendation set out in the guideline. For example, in 2014, the guidelines in both the United States and South Korea suggested performing FNAC when tumor size was over $0.5 \mathrm{~cm}(32,33)$, but the court judged that FNAC should be performed even when tumor size was $0.4 \mathrm{~cm}$. In addition, the court judged that a re-examination should be performed, even though FNAC was previously performed at another hospital (Table 4). This situation is not unique to South Korea. According to Lydyiatt (34), the US court judged that the false-negative case of FNAC was not medical malpractice, while that "not performing FNAC" was medical malpractice. Therefore, performing FNAC more actively may be a way to prevent unnecessary lawsuits. In practice, guidelines are not strictly required standards but recommendations (35), so it is appropriate to apply them according to the individual patient's condition or the judgment of the surgeon. On the other hands, in the case of FSE, in contrast to FNAC, there were no disputes arising out of cases when the surgeon did not perform the examination. The effectiveness of FSE is still controversial (36-38); therefore, conservative implementation of FSE may be a way to prevent disputes. Nevertheless, if the surgeon determines that the FSE is necessary, the surgeon should fully discuss with the patient and his family before surgery possible plans and scenarios according to FSE results that will be revealed during the surgery. Our study showed that the court regarded as malpractice if surgeon do not explain FSE result to the patient's family during surgery or do not consider to narrow the extent of surgery even though FSE result turned out non-cancer during surgery. However, it is commonly impossible to explain FSE results to patients and their family during surgery. Therefore, it is important to obtain informed consent on surgery including FSE after fully explaining to patients both the reason that FSE is needed and the possible options according to the FSE results.

In this study, cases of physician's violation of liability for explanation were various (Figure 2). Insufficient explanation may be the cause of dispute because it hinders the formation of trust with patients (39). Physicians should be aware that providing information to patients is the most fundamental obligation of the physician $(40,41)$, and patients should only give informed consent to undergo surgery based on sufficient information. Shared decisionmaking can be considered an effective method of providing an environment of self-determination for the patients $(42,43)$. In shared decision-making, the physician provides sufficient non-biased information that the patient considers, and the final treatment direction is decided by the physician and patient together based on the patient's values and preferences $(42,43)$. Although this requires the physician to spend more time explaining and waiting for the patient to decide on the final direction of treatment, it is suitable for non-urgent surgeries such as thyroidectomy. Nevertheless, it is impossible to predict and explain all possible risks before surgery, because each patient's characteristics is different. Some disputes may arise even if informed consent is appropriately obtained before surgery. Therefore, building solid trust with patients may be the best way to prevent medical disputes. Various studies have shown that rapport formation, adequate communication, and good bedside manner help reduce medical disputes (44-46).

This study has some limitations. First, as not all disputes go to court, the judgments we analyzed did not include all disputes related to thyroidectomy arising in South Korea. Thus, the results of this study may not fully reflect malpractice involving thyroidectomy. Second, the judgments did not contain detailed clinical information on patients and surgery; the collection of information was limited, making it difficult to access the analysis from multiple perspectives. Third, the results of this South Korean study may not be representative worldwide, as the characteristics of lawsuits for thyroidectomy may vary across countries according to their social and cultural backgrounds. Fourth, the number of judgments was small compared to previous studies (Table S1) $(12-14,25,26)$, making it difficult to reflect all characteristics of thyroidectomy fully.

Despite these limitations, the study is meaningful in being the first to deal with medical disputes in South Korea, which has the highest incidence of thyroid cancer worldwide and a high number of thyroid surgeries. This study will not only provide useful information about medical malpractice to doctors and practitioners involved in thyroid surgery but will also be used as a basis for preparing measures to prevent recurrence. 


\section{Acknowledgments}

Funding: None.

\section{Footnote}

Reporting Checklist: The authors have completed the MDAR and STROBE reporting checklist. Available at http://dx.doi. org/10.21037/gs-20-398

Data Sharing Statement: Available at http://dx.doi. org/10.21037/gs-20-398

Conflicts of Interest: All authors have completed the ICMJE uniform disclosure form (available at http://dx.doi. org/10.21037/gs-20-398). The authors have no conflicts of interest to declare.

Ethical Statement: The authors are accountable for all aspects of the work in ensuring that questions related to the accuracy or integrity of any part of the work are appropriately investigated and resolved. Institutional review board (IRB) approval was not necessary for this retrospective study that utilized written court judgments since it was impossible for researchers to collect personally identifiable information and identify individuals through the collection method they utilized. The study was conducted in accordance with the Declaration of Helsinki (as revised in 2013).

Open Access Statement: This is an Open Access article distributed in accordance with the Creative Commons Attribution-NonCommercial-NoDerivs 4.0 International License (CC BY-NC-ND 4.0), which permits the noncommercial replication and distribution of the article with the strict proviso that no changes or edits are made and the original work is properly cited (including links to both the formal publication through the relevant DOI and the license). See: https://creativecommons.org/licenses/by-nc-nd/4.0/.

\section{References}

1. Kuhn MA, Bloom G, Myssiorek D. Patient Perspectives on Dysphonia After Thyroidectomy for Thyroid Cancer. J Voice 2013;27:111-4.

2. Ta JH, Liu YF, Krishna P. Medicolegal Aspects of Iatrogenic Dysphonia and Recurrent Laryngeal Nerve Injury. Otolaryngol Head Neck Surg 2016;154:80-6.
3. Nouraei SAR, Allen J, Kaddour H, et al. Vocal palsy increases the risk of lower respiratory tract infection in low-risk, low-morbidity patients undergoing thyroidectomy for benign disease: A big data analysis. Clin Otolaryngol 2017;42:1259-66.

4. Gardner GM, Smith MM, Yaremchuk KL, et al. The cost of vocal fold paralysis after thyroidectomy. Laryngoscope 2013;123:1455-63.

5. Vaccarella S, Dal Maso L, Laversanne M, et al. The Impact of Diagnostic Changes on the Rise in Thyroid Cancer Incidence: A Population-Based Study in Selected High-Resource Countries. Thyroid 2015;25:1127-36.

6. Ahn HS, Kim HJ, Kim KH, et al. Thyroid Cancer Screening in South Korea Increases Detection of Papillary Cancers with No Impact on Other Subtypes or Thyroid Cancer Mortality. Thyroid 2016;26:1535-40.

7. Bray F, Ferlay J, Soerjomataram I, et al. Global cancer statistics 2018: GLOBOCAN estimates of incidence and mortality worldwide for 36 cancers in 185 countries. CA Cancer J Clin 2018;68:394-424.

8. Korea Central Cancer Registry. Annual report of cancer statistics in Korea in 2016. Sejong: Ministry of Health and Welfare, 2018:207.

9. National Health Insurance Service. Main Surgery Statistical Yearbook for 2017. Wonju: National Health Insurance Service, 2018:484.

10. Chang D. A Study on Patient-Physician Ralation Based on Conception of Contract. J Humanit 2013;51:161-82.

11. Lee DP. Current Status of Medical Disputes, Prospects and Cautions. Korean J Med 2019;94:231-6.

12. Dralle H, Lorenz K, Machens A. Verdicts on malpractice claims after thyroid surgery: Emerging trends and future directions. Head Neck 2012;34:1591-6.

13. Singer MC, Iverson KC, Terris DJ. Thyroidectomyrelated malpractice claims. Otolaryngol - Head Neck Surg 2012;146:358-61.

14. Gartland RM, Bloom JP, Parangi S, et al. A Long, Unnerving Road: Malpractice Claims Involving the Surgical Management of Thyroid and Parathyroid Disease. World J Surg 2019;43:2850-5.

15. Gambardella C, Polistena A, Sanguinetti A, et al. Unintentional recurrent laryngeal nerve injuries following thyroidectomy: Is it the surgeon who pays the bill? Int J Surg 2017;41:S55-9.

16. Cannizzaro MA, Bianco S, Picardo MC, et al. How to avoid and to manage post-operative complications in thyroid surgery. Updates Surg 2017;69:211-5.

17. Hayward NJ, Grodski S, Yeung M, et al. Recurrent 
laryngeal nerve injury in thyroid surgery: a review. ANZ J Surg 2013;83:15-21.

18. Abadin SS, Kaplan EL, Angelos P. Malpractice litigation after thyroid surgery: The role of recurrent laryngeal nerve injuries, 1989-2009. Surgery 2010;148:718-22; discussion 722-3.

19. Alesina PF, Hinrichs J, Meier B, et al. Intraoperative Neuromonitoring for Surgical Training in Thyroid Surgery: Its Routine Use Allows a Safe Operation Instead of Lack of Experienced Mentoring. World J Surg 2014;38:592-8.

20. Bae DS, Kim S-JJ. Intraoperative neuromonitoring of the recurrent laryngeal nerve in robotic thyroid surgery. Surg Laparosc Endosc Percutan Tech 2015;25:23-6.

21. Vasileiadis I, Karatzas T, Charitoudis G, et al. Association of intraoperative neuromonitoring with reduced recurrent laryngeal nerve injury in patients undergoing total thyroidectomy. JAMA Otolaryngol Head Neck Surg 2016;142:994-1001.

22. Sarkis LM, Zaidi N, Norlén O, et al. Bilateral recurrent laryngeal nerve injury in a specialized thyroid surgery unit: would routine intraoperative neuromonitoring alter outcomes? ANZ J Surg 2017;87:364-7.

23. Al-Qurayshi Z, Kandil E, Randolph GW. Costeffectiveness of intraoperative nerve monitoring in avoidance of bilateral recurrent laryngeal nerve injury in patients undergoing total thyroidectomy. Br J Surg 2017;104:1523-31.

24. Schneider R, Randolph GW, Dionigi G, et al. International neural monitoring study group guideline 2018 part I: Staging bilateral thyroid surgery with monitoring loss of signal. Laryngoscope 2018;128:S1-17.

25. Dent PC, Bagnall NM. Litigation in thyroid surgery in England. Br J Hosp Med (Lond) 2017;78:213-8.

26. Wijekoon TD, Gonzalez-Pena DE, Balasubramanian SP. Evaluation of malpractice litigation in thyroid disease in the National Health Service. Postgrad Med 2019;131:607-11.

27. Seo DW. History of intraoperative neurophysiological monitoring in Korea. J Intraoperative Neurophysiol 2019;1:1-8.

28. Stack BC, Angelos P. The ethics of disclosure and counseling of patients with thyroid cancer. JAMA Otolaryngol - Head Neck Surg 2015;141:957-8.

29. Yi K-I, Ahn S, Park DY, et al. False-positive cytopathology results for papillary thyroid carcinoma: A trap for thyroid surgeons. Clin Otolaryngol 2017;42:1153-60.

30. Singer PA, Cooper DS, Daniels GH, et al. Treatment
Guidelines for Patients With Thyroid Nodules and Well-Differentiated Thyroid Cancer. Arch Intern Med 1996;156:2165-72.

31. Kim WB, Kim TY, Kwon HS, et al. Management Guidelines for Patients with Thyroid Nodules and Thyroid Cancer. J Korean Soc Endocrinol 2007;22:157-87.

32. Cooper DS, Doherty GM, Haugen BR, et al. Revised American Thyroid Association Management Guidelines for Patients with Thyroid Nodules and Differentiated Thyroid Cancer. Thyroid 2009;19:1167-214.

33. Yi KH, Park YJ, Koong SS, et al. Revised Korean Thyroid Association Management Guidelines for Patients with Thyroid Nodules and Thyroid Cancer. Korean J Otorhinolaryngol-Head Neck Surg 2011;54:8-36.

34. Lydiatt DD. Medical malpractice and the thyroid gland. Head Neck 2003;25:429-31.

35. Haugen BR, Alexander EK, Bible KC, et al. 2015 American Thyroid Association Management Guidelines for Adult Patients with Thyroid Nodules and Differentiated Thyroid Cancer: The American Thyroid Association Guidelines Task Force on Thyroid Nodules and Differentiated Thyroid Cancer. Thyroid 2016;26:1-133.

36. Makay O, ICOZ G, GURCU B, et al. The Ongoing Debate In Thyroid Surgery: Should Frozen Section Analysis Be Omitted? Endocr J 2007;54:385-90.

37. Najah H, Tresallet C. Role of frozen section in the surgical management of indeterminate thyroid nodules. Gland Surg 2019;8:S112-7.

38. Grisales J, Sanabria A. Utility of Routine Frozen Section of Thyroid Nodules Classified as Follicular Neoplasm: Meta-Analysis of Diagnostic Tests. Am J Clin Pathol 2020;153:210-20.

39. Gabay G, Bokek-Cohen Y. Infringement of the right to surgical informed consent: negligent disclosure and its impact on patient trust in surgeons at public general hospitals - the voice of the patient. BMC Med Ethics 2019;20:77.

40. Matusitz J, Spear J. Effective doctor-patient communication: An updated examination. Soc Work Public Health 2014;29:252-66.

41. Cainzos MA, González-Vinagre S. Informed consent in surgery. World J Surg 2014;38:1587-93.

42. Schoenfeld EM, Mader S, Houghton C, et al. The Effect of Shared Decisionmaking on Patients' Likelihood of Filing a Complaint or Lawsuit: A Simulation Study. Ann Emerg Med 2019;74:126-36.

43. Brito JP, Castaneda-Guarderas A, Gionfriddo MR, et al. Development and Pilot Testing of an Encounter Tool for 
Shared Decision Making About the Treatment of Graves' Disease. Thyroid 2015;25:1191-8.

44. Lydiatt DD. Medical Malpractice and Facial Nerve Paralysis. Arch Otolaryngol Head Neck Surg 2003;129:50-3.

45. Tucker JD, Cheng Y, Wong B, et al. Patient-physician

Cite this article as: Choi S, Shin S, Lee W, Choi SM, Kang SW. Medicolegal lessons learned from thyroidectomyrelated lawsuits: an analysis of judicial precedents in South Korea from 1998 to 2019. Gland Surg 2020;9(5):1286-1297. doi: $10.21037 / g s-20-398$ mistrust and violence against physicians in Guangdong Province, China: a qualitative study. BMJ Open 2015;5:e008221.

46. Ock M, Choi EY, Jo MWW, et al. Evaluating the expected effects of disclosure of patient safety incidents using hypothetical cases in Korea. PLoS One 2018;13:e0199017. 
Supplementary

Table S1 Comparison of previous research analyzing claims related to thyroid surgery

\begin{tabular}{|c|c|c|c|c|c|c|}
\hline Characteristics & Dralle et al., 2012 & Singer et al., 2012 & Dent et al., 2017 & Gartland et al., 2019 & Wijekoon et al., 2019 & Ours \\
\hline Country & Germany & USA & UK & USA & UK & South Korea \\
\hline Source & $\begin{array}{l}\text { Institutional expert } \\
\text { opinions }\end{array}$ & $\begin{array}{c}\text { Physicians } \\
\text { Insurers Association of } \\
\text { America malpractice } \\
\text { claims database }\end{array}$ & $\begin{array}{l}\text { NHS Litigation } \\
\text { Authority } \\
\text { database }\end{array}$ & $\begin{array}{c}\text { Controlled Risk } \\
\text { Insurance Company } \\
\text { Strategies' Comparative } \\
\text { Benchmarking System } \\
\text { malpractice claims } \\
\text { database }\end{array}$ & $\begin{array}{c}\text { NHS Litigation } \\
\text { Authority database }\end{array}$ & $\begin{array}{l}\text { Supreme court of } \\
\text { Korea's written } \\
\text { judgment management } \\
\text { system database }\end{array}$ \\
\hline Covered period & 1995 to 2010 & 1985 to 2008 & 1995.1 to 2012.7 & 1995 to 2015 & 2002.4 to 2016.11 & 1998.1 to 2019.7 \\
\hline Number of total cases & 75 & 380 & 161 & 128 & 189 & 35 \\
\hline \multicolumn{7}{|l|}{ Alleged adverse event, $\mathrm{n}(\%)^{\dagger}$} \\
\hline Vocal cord palsy and/or RLN injury & $43(57.3)$ & $55(14.5)$ & $33(20.5)$ & $39(30.5)$ & $12^{\dagger \dagger}(6.3)$ & $7(20.0)$ \\
\hline Hypocalcemia with hypoparathyroidism & $21(28.0)$ & $9(2.4)$ & $6^{\ddagger}(3.7)$ & $10(7.8)$ & $3^{\dagger \dagger}(1.6)$ & $3(8.6)$ \\
\hline Unnecessary surgery & $\mathrm{N} / \mathrm{I}$ & $\mathrm{N} / \mathrm{I}$ & $2^{\S}(1.2)$ & $5^{\pi}(3.9)$ & $16^{\dagger \dagger}(8.5)$ & $7(20.0)$ \\
\hline Delayed diagnosis & $\mathrm{N} / \mathrm{I}$ & $\mathrm{N} / \mathrm{I}$ & $40(24.8)$ & $\mathrm{N} / \mathrm{I}$ & $22^{\dagger \dagger}(11.6)$ & $4(11.4)$ \\
\hline Bleeding/hematoma & $7(9.3)$ & $\mathrm{N} / \mathrm{I}$ & $\mathrm{N} / \mathrm{I}$ & $18(14.1)$ & $\mathrm{N} / \mathrm{I}$ & 5 (14.3) \\
\hline IONM for RLN & $\begin{array}{l}3 \text { cases without } \\
\text { using IONM were ruled } \\
\text { as malpractice }\end{array}$ & No case on IONM & No case on IONM & No case on IONM & No case on IONM & No case on IONM \\
\hline
\end{tabular}

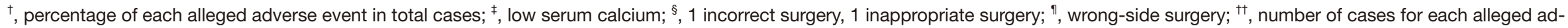

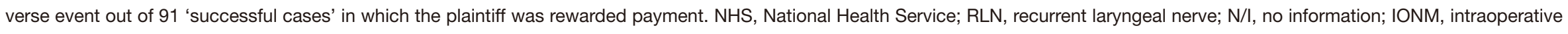
neural monitoring. 